Breitwieser, J., Neubauer, A. B., \& Brod, G. (2021). Incremental validity of online over offline reports of volitional control in predicting learning success. Zeitschrift für Entwicklungspsychologie und Pädagogische Psychologie [German Journal of Developmental and Educational Psychology]. https://doi.org/10.1026/0049$\underline{8637 / \mathrm{a} 000219}$

\title{
Incremental validity of online over offline reports of volitional control in predicting
}

\section{learning success}

\author{
Jasmin Breitwieser ${ }^{\mathrm{a}}$, Andreas B. Neubauer ${ }^{\mathrm{a}}$, and Garvin Brod ${ }^{\mathrm{a}, \mathrm{b}}$ \\ ${ }^{\text {aDIPF }}$ | Leibniz Institute for Research and Information in Education, Frankfurt am \\ Main, Germany; ${ }^{\mathrm{b}}$ Goethe University Frankfurt, Frankfurt am Main, Germany
}

Author Note

Jasmin Breitwieser, Education and Human Development, DIPF | Leibniz Institute for Research and Information in Education, Frankfurt am Main, Germany; Andreas B. Neubauer, Education and Human Development, DIPF | Leibniz Institute for Research and Information in Education, Frankfurt am Main, Germany; Garvin Brod, Education and Human Development, DIPF | Leibniz Institute for Research and Information in Education/Department of Psychology, Goethe University Frankfurt, Frankfurt am Main, Germany.

This research was supported by the "Vereinigung von Freunden und Förderern der Goethe-Universität”. G.B. was supported by a Jacobs Foundation Early Career Research Fellowship. 
Correspondence concerning this article should be addressed to Jasmin Breitwieser, DIPF | Leibniz Institute for Research and Information in Education, Rostocker Str. 6, 60323 Frankfurt am Main, Germany. E-mail: breitwieser@dipf.de

This paper is not the copy of record and may not exactly replicate the authoritative document published in the Zeitschrift für Entwicklungspsychologie und Pädagogische Psychologie [German Journal of Developmental and Educational Psychology]. The final article is available at: https://doi.org/10.1026/0049-8637/a000219 


\begin{abstract}
Volitional control (i.e., efforts to maintain goal striving in the face of obstacles) is an integral part of self-regulated learning and an important factor for explaining individual differences in academic performance. However, differences between the various methods for assessing volitional control have rarely been investigated. Two common methods are a) offline questionnaires, in which respondents aggregate experiences over a longer period of time, and b) online questionnaires such as learning diaries, which assess respondents' experiences close to the learning event. We compared these assessment approaches in 96 medical students who prepared for a high-stakes exam. Achievement of self-set learning goals was measured objectively via log-files of students' activities on a learning platform. Daily reports of volitional control explained substantial variance in achievement of learning goals over and above the offline questionnaire, indicating incremental validity of online assessments of self-regulation. Moreover, the daily reports of volitional control could explain intra-individual day-to-day variance in goal achievement. The current study, thus, suggests that learning diaries, albeit cumbersome, have clear advantages over offline questionnaires.
\end{abstract}

Keywords: volitional control, learning diaries, self-regulated learning, ambulatory assessment, retrospective assessment 


\section{Incremental validity of online over offline reports of volitional control in predicting learning success}

Even highly motivated learners can fail. While motivation is needed to set a specific learning goal and commit to it, it is not sufficient to overcome the roadblocks in the process of goal striving. As distractions, interruptions, and the activation of competing goals are nearly unavoidable during the pursuit of academic goals (Corno, 1994; Duckworth et al., 2019), volitional control forms an integral part of self-regulated learning (SRL) (Boekaerts \& Corno, 2005; Corno, 1993; Pintrich, 2004; Schmitz \& Wiese, 2006; Zimmerman, 2000). Volitional control refers to regulating activities aimed at maintaining efforts in the face of obstacles (Kuhl, 1985, 2000). While some researchers reserve the term volitional control for the control of motivation, emotions, and environment (e.g., Pintrich et al., 2000; see also Wolters, 2003), we follow a broader conceptualization that includes the control of information processing around goals (Corno, 1993; Corno \& Kanfer, 1993; Kuhl, 1985).

\section{Offline and Online Assessments of Volitional Control}

Volitional control is considered to be an important factor for explaining individual differences in academic performance due to its central role in the self-regulation of learning (Corno, 1993). To empirically test the relation between volitional control and performance, the assessment of volitional control plays a critical role. Researchers employ various different instruments such as questionnaires, interviews, direct observations, and performance tasks to assess volitional control (see Corno, 1994). The differences between these instruments have rarely been examined systematically, however. Self-reports are the most widely used method for the assessment of volitional 
control, but even within this category, instruments differ substantially. Part of these differences can be attributed to the different conceptualizations of volitional control within the SRL framework. Assessments that are conducted separately from the learning event (i.e., offline) are typically decontextualized and tap models of SRL that emphasize its trait-like aspects (Boekaerts \& Corno, 2005). Online measures, on the other hand, are conducted around the same time as the learning event and typically directly relate to the learning context at hand. They are predominantly used in the context of process models of SRL, which emphasize the dynamic, state-like nature of SRL (e.g., Schmitz \& Wiese, 2006; Zimmerman, 2000). As we outline below, offline and online self-reports typically differ in contextualization, proneness to biases, and the effort that goes into the assessment.

Offline assessments of volitional control such as standardized questionnaires (e.g., Dörrenbächer \& Perels, 2015; McCann \& Garcia, 1999; Wolters, 1999) typically require learners to remember and abstract from multiple past learning situations and aggregate their experience over longer periods of time (Winne \& Perry, 2000). Thus, inasmuch as offline assessments are decontextualized, they measure perceived typical rather than situational behavior (cf. Wennerhold \& Friese, 2020). Therefore, they critically rely on students' ability to select valid events of interest, recall them correctly, and aggregate them appropriately (Rausch, 2014; Veenman, 2011). Biases may arise if students miss to encode relevant events, are unable to retrieve them, or fill in memory gaps when reconstructing incomplete memories (Tourangeau, 2000) or generalized self-beliefs (Robinson \& Clore, 2002). Recall biases are, thus, a serious validity threat to offline selfreport assessments. 
Online assessments of volitional control are typically highly contextualized and measure situational rather than typical behavior. Learning diaries, for instance, are a prominent example of an ambulatory assessment instrument (Conner \& Mehl, 2015) often used when trying to capture the situation-specific nature of SRL (e.g., Liborius et al., 2019; Perels et al., 2007; Schmitz \& Perels, 2011; Schmitz \& Wiese, 2006; Wallin \& Adawi, 2018). Diaries allow to gather data close to the learning session while being able to cover the whole self-regulation cycle, which comprises a pre-action, an action, and a post-action phase (Schmitz \& Wiese, 2006; Zimmerman, 2000). Learning diary studies typically assess action phase components of SRL such as volitional control after the learning session to not interrupt learning (e.g., Liborius et al., 2019; Schmitz \& Perels, 2011; Schmitz \& Wiese, 2006). Although recall biases might, thus, not be completely eliminated (Veenman, 2011), they are kept relatively small in comparison with questionnaires that require students to aggregate over much longer periods of time.

However, online assessments such as learning diaries also come with costs. First, assessing momentary or very recent experiences repeatedly can lead to reactivity effects where the frequency of self-regulation efforts increase due to repeated measurement (Korotitsch \& Nelson-Gray, 1999). Reactivity effects are not always unwanted. In recent years, learning diaries are concurrently used as a combination of both an assessment and an intervention tool (Klug et al., 2011; Panadero et al., 2016). Reactivity effects are, however, problematic if the focus lies on testing the unique contribution of SRL to academic achievement in the absence of any interventions (Korotitsch \& Nelson-Gray, 1999). Second, as of yet, there are no standardized instruments for assessing volitional control online, which makes it difficult to compare the results of different studies. There 
is hardly any overlap between the items used in different learning diary studies as they need to be adapted to the specific learning contexts under investigation. Therefore, there are no general guidelines for their interpretation. Third, learning diaries are cumbersome, demanding high levels of compliance and effort from study participants. High dropout rates are, thus, rather common, with a recent diary study reporting an exclusion of $54.74 \%$ of participants who did not meet the minimum participation rate over the 22 week long study period (Liborius et al., 2019).

\section{Volitional Control and Learning Success}

Considering that both online and offline self-report assessments have their assets and drawbacks, how do they compare with regards to explaining individual differences in learning success? Overall, the data basis is much larger for offline self-report assessments. A meta-analysis that included many questionnaire measures of SRL revealed that effort regulation, which represents a mix of different aspects of volitional control, had a medium correlation with grade point average in university students (Richardson et al., 2012). Similarly, a recent review that covered a broader range of outcome measures came to the conclusion that self-control predicts academic attainment, academic course grades, as well as scores on standardized achievement tests (Duckworth et al., 2019). Together, these results suggest that offline self-report measures of aspects of volitional control do at least have some explanatory power for inter-individual differences in academic performance. But how do they compare to online assessments?

There are only few learning diary studies which included items on volitional control. One study assessed concentration, self-motivation, and procrastination in their learning diaries, all of which predicted daily learning outcomes (e.g., study time, 
satisfaction with learning) (Schmitz \& Wiese, 2006). There was also considerable day-today variance in these variables, indicating that volitional control contains situationspecific state aspects. However, the authors did not analyze whether these fluctuations were coupled with day-to-day changes in the outcome variables. A recent learning diary study provided evidence for this intra-individual coupling (Liborius et al., 2019): Students were more satisfied with their studies on days on which they procrastinated less and put more effort into studying. However, there was no test of inter-individual differences, that is, whether students who procrastinated less and put more effort into studying were overall more satisfied than students with less volitional control. In summary, the evidence from learning diary studies is still comparably scarce and limited to subjective learning outcomes instead of objective measures of learning success or academic achievement. The available findings suggest that treating volitional control as a situation-specific state allows to explain variance in immediate learning outcomes such as study satisfaction.

\section{The Present Study}

The high costs associated with repeated, ambulatory assessments create a clear need to establish their incremental validity over more economic instruments such as offline questionnaires (Trull \& Ebner-Priemer, 2013). However, there are still only few studies that have systematically compared online and offline measures of volitional control. Research on self-control has focused on the comparison between questionnaires and behavioral measures, finding little to no convergence between them (e.g., Duckworth \& Kern, 2011; Rovers et al., 2019; Saunders et al., 2018; Wennerhold \& Friese, 2020). A meta-analysis which directly compared online and offline assessments of SRL in their 
correlation with academic performance reported higher correlations for online measures such as behavior during task (Dent \& Koenka, 2016). However, there was no inclusion of self-reports as online measures. Matters are further complicated by the use of different outcome measures across studies. Questionnaires are predominantly used when trying to explain inter-individual differences in overall academic performance (e.g., grade point average), whereas learning diary studies rely on immediate and subjective learning outcomes (e.g., satisfaction with learning).

The purpose of the present study was, thus, to compare two common assessment methods of volitional control regarding their validity for explaining individual differences in learning success. Medical students preparing for a high-stakes exam reported how frequently they used volitional control when learning for the exam. This one-off assessment was contrasted with daily assessments of students' volitional control during four weeks of learning for the exam. Our outcome measures of interest were: a) daily goal achievement, which we operationalized objectively via logfiles of students' performance on a learning platform, and b) exam performance. We expected the volitional control measures obtained from both assessment methods to explain interindividual differences in the outcome measures, in line with prior studies that have shown that volitional control is an important predictor of academic achievement (Richardson et al., 2012). Based on the evidence for greater power of online over offline measures of SRL in predicting achievement (Dent \& Koenka, 2016), we further hypothesized that the daily assessments would give a more accurate reflection of students' actual volitional control. This should play out in additional explained variance over and above the offline measure. Finally, we expected to find a positive correlation between day-to-day 
fluctuations in reported volitional control and goal achievement. This within-person association has been shown before for volitional control and subjective learning outcomes (e.g., Liborius et al., 2019), whereas we sought to demonstrate it with an objective measure of learning goal achievement.

\section{Method}

\section{Participants}

We recruited medical students from all over Germany who intended to take the second state exam in October 2018 and used the popular digital learning platform AMBOSS as their main source for preparation. Students who fit these criteria were recruited via the platform's database.

The present study was part of a larger project which included a self-regulation intervention (see Breitwieser et al., 2020; an overview of the procedure and all materials used as part of the project can be found at https://osf.io/tg7zd/?view_only=58ad6b4f10994f878625d713f2069a0c). We first checked whether the intervention had a significant effect on the target measures of the present study and, as this was the case, decided to only include students of the control group in our analyses. Of 119 control students, 117 filled out the learning diaries for at least one day, 109 of which also filled out the posttest survey. We excluded two students who set unrealistically high learning goals (> $3 \mathrm{SD}$ above the sample mean) and ten students who filled out less than 25 diaries to obtain a representative score of volitional control and 
learning goal achievement for the investigation of inter-individual differences ${ }^{1}$.

Furthermore, we only included measures from days on which students had set a goal and on which the time between goal setting and the post-learning diary did not exceed 24 hours (exclusion of $13.89 \%$ of the daily data) because otherwise the diary data would not have been meaningful to interpret. The final sample, thus, consisted of 96 students $(71.88 \%$ female, mean age $=26.16$ years, range $=22-53$ years $)$ with a total of 2,932 measurement occasions.

All participants gave written informed consent prior to testing. Participants received 1 Euro for each day of the learning diary period with complete data and a bonus of 10 Euro if they had provided complete data for at least 30 days. Ethics approval was obtained from the ethics committee of DIPF | Leibniz Institute for Research and Information in Education.

\section{Procedure and Measures}

\section{Learning Diaries}

A detailed description of the procedure can be found in Breitwieser et al. (2020). In short, participants filled out a pre- and a post-learning diary daily for up to 40 days, starting 64 days before the exam. Links to the web-based questionnaires were sent to

\footnotetext{
${ }^{1}$ As the criterion of 25 days was rather arbitrary, based on the distribution of
} students' participation rate, we conducted a sensitivity analysis to see if the results were biased due to our choice of this exclusion criterion. We found that the pattern of results remained the same when not excluding any participants or when excluding participants with less than 20 days. 
participants via e-mail. Participants were instructed to fill out the pre-learning diary just before they started learning and the post-learning diary directly after they finished learning. The questionnaires were constructed to cover the whole self-regulation cycle, with the pre-learning diary covering pre-action phase components, and the post-learning diary covering action and post-action phase components (cf. Schmitz \& Wiese, 2006).

Goal setting was measured with one item in the pre-learning diary. The goal pertained to the number of questions participants planned to answer on the learning platform, as answering old exam questions (all in multiple choice format) was students' primary learning activity. Participants typed the number in a text field. The actual number of questions a participant had answered on any given day was determined via log-files which we received from the learning platform. Daily goal achievement was operationalized as a dichotomous variable (i.e., goal achieved vs. missed).

Volitional control was measured in the post-learning diary, operationalized as a composite score of the regulation of one's thoughts, feelings, and actions during learning. We also included procrastination as failure to overcome detrimental behavior (Dörrenbächer \& Perels, 2016; Kuhl, 2000) and self-monitoring as an attentional control strategy to detect deviations from desired behavior (Duckworth et al., 2019). Regulation, procrastination, and self-monitoring were measured on a 5-point Likert scale $(1=$ "strongly disagree"; 5 = "strongly agree"). The items can be found in Appendix A. They were constructed on the basis of SRL models that explicitly include volitional strategies (Pintrich, 2004; Schmitz \& Wiese, 2006) and were, in part, adapted from existing scales (cf. Dörrenbächer \& Perels, 2016; Schwarzer \& Jerusalem, 1999). The final selection of items was chosen on the basis of data from a pilot study with 36 students. To obtain a 
composite score of volitional control from the diary data, we computed the mean of all items (procrastination was inverted prior to aggregation), weighted by the number of items per volitional control facet (i.e., self-monitoring, regulation, and procrastination). The weighted mean ensured that the score was comparable to the score from the posttest questionnaire, which differed in the number of items per facet.

The internal consistency of the diary measure was good on both the within- $(\omega=$ $.84)$ and the between-level $(\omega=.92)$. Reliability of the composite score over time was estimated via odd-even stability and split-half stability. We calculated the odd-even coefficient by dividing the days for each person into one group with the even numbered days and one group with odd numbered days, calculating the composite scores for each group and correlating them. The split-half coefficient was calculated by dividing each student's measurement period in two halves and correlating the composite scores of the first half with the composite scores of the second half. The high stability of the composite scores (odd-even: $r(94)=.93$; split-half: $r(94)=.82$ ) justifies its use as an interindividual score (cf. Schmitz \& Skinner, 1993).

\section{Posttest Questionnaire}

After the daily assessment period, students filled out a posttest questionnaire in which they reported how often they typically exerted volitional control when learning for the exam. The reports can be considered retrospective in that they were likely based on students' experiences during the previous weeks of exam preparation. Thus, the aggregated diary reports and the questionnaire reports relate to roughly the same time period. Like the score from the diary data, volitional control was operationalized as a composite score of self-monitoring and regulation as well as failed regulation (i.e., 
procrastination) of learning. Regulation, procrastination, and self-monitoring were measured with three items each on a 5-point Likert scale ("never" - "rarely" "sometimes" - "frequently" - "very frequently"). The items can be found in Appendix B. The construction and selection of items followed the same procedure as described for the learning diary items. As for the diary score, the questionnaire score was calculated by computing the weighted mean. The questionnaire score had a moderate-to-high internal consistency $(\omega=.79)$.

\section{Exam Results}

We asked participants to report the results of their written exam (\% of questions correctly answered) four weeks after the exam had taken place. All but one student provided information on the results of their written exam. 80 of 96 students also reported the result of the intermediate exam ('Physikum') as a measure of prior achievement.

\section{Data Analysis}

We compared the explanatory power of an offline assessment of volitional control (i.e., the questionnaire score) and an online assessment of volitional control (i.e., the diary score) for learning success. Learning success was operationalized via two dependent variables: a) achievement of daily learning goals, and b) exam performance.

We computed a two-step hierarchical multilevel logistic regression analysis to test if the diary score explained inter-individual differences in daily goal achievement over and above the questionnaire score. To this end, we first entered the questionnaire score into the model (between-level), before additionally entering the diary score (between- and within-level). We included the full random effects structure in the second step of the 
model (i.e., estimating random intercepts and random slopes for the effect of the diary score on goal achievement).

Since the questionnaire score can only explain inter-individual variance in goal achievement, a fair comparison with the diary score can only be performed on the between-level of the model. However, applying a multilevel procedure allowed us to additionally test whether day-to-day fluctuations in volitional control as contained in the diary score $(\mathrm{ICC}=.36$ ) were coupled with day-to-day fluctuations in goal achievement (within-level). We similarly computed a two-step hierarchical regression analysis to test the incremental validity of the diary score for exam performance.

All analyses were conducted in Mplus (Muthén \& Muthén, 1998-2017), using a Bayesian estimation procedure with default (uninformative) priors. Computations were run with 5,000 iterations and a thinning factor of 200 . We report $90 \%$ credible intervals (CI) in addition to point estimates. CIs quantify the amount of posterior uncertainty in the coefficients by giving the interval that the parameter falls in with a certain probability, given the data. $90 \%$ CIs correspond to a $5 \%$ probability for the parameter to be larger than the upper limit of the interval. With uninformative priors, this procedure translates into a one-tailed test at $\alpha=.05$ in a frequentist framework, thus reflecting our directed hypotheses of positive associations between all measures.

\section{Results}

Students' average score from the diary data was slightly above the midpoint of the 5-point Likert scale, and the same was the case for the questionnaire score (see Table 1). The means of these measures cannot be compared directly, however, as they comprised different items that were answered on different response scales. The average diary score 
indicates that students said that they exerted aspects of volitional control to some extent across days, whereas the questionnaire score indicates that students said that they typically exert aspects of volitional control occasionally or frequently. There was a strong correlation between the average diary score and the questionnaire score (see Figure 1), with a shared variance of $53 \%$ (CI [41\%, 69\%]).

Table 1. Descriptive Statistics.

\begin{tabular}{|c|c|c|c|c|c|c|c|}
\hline & & $\begin{array}{c}\text { Mean } \\
(S D)\end{array}$ & Range & 2 & 3 & 4 & 5 \\
\hline 1 & Diary Score ${ }^{\mathrm{a}}$ & $\begin{array}{c}3.63 \\
(0.52)\end{array}$ & $2.11-4.67$ & $\begin{array}{c}.73 \\
{[.64, .83]}\end{array}$ & $\begin{array}{c}.13 \\
{[-.06, .41]}\end{array}$ & $\begin{array}{c}.29 \\
{[.12, .51]}\end{array}$ & $\begin{array}{c}.13 \\
{[-.04, .38]}\end{array}$ \\
\hline 2 & $\begin{array}{c}\text { Questionnaire } \\
\text { Score }\end{array}$ & $\begin{array}{c}3.59 \\
(0.46)\end{array}$ & $2.37-4.70$ & & $\begin{array}{c}.07 \\
{[-.12, .35]}\end{array}$ & $\begin{array}{c}.19 \\
{[.02, .43]}\end{array}$ & $\begin{array}{c}.12 \\
{[-.06, .37]}\end{array}$ \\
\hline 3 & $\begin{array}{l}\text { Intermediate } \\
\text { exam }^{\mathrm{b}}\end{array}$ & $\begin{array}{l}78.81 \\
(7.74)\end{array}$ & $64.00-93.00$ & & & $\begin{array}{c}.08 \\
{[-.12, .37]}\end{array}$ & $\begin{array}{c}.80 \\
{[.68, .90]}\end{array}$ \\
\hline 4 & $\begin{array}{c}\text { Daily Goal } \\
\text { achievement }^{\mathrm{a}, \mathrm{b}}\end{array}$ & $\begin{array}{c}70.10 \\
(24.39)\end{array}$ & $9.68-100$ & & & & $\begin{array}{c}-.05 \\
{[-.22, .22]}\end{array}$ \\
\hline 5 & $\begin{array}{c}\text { Exam } \\
\text { performance }^{b}\end{array}$ & $\begin{array}{l}80.19 \\
(6.38)\end{array}$ & $52.00-92.00$ & & & & \\
\hline
\end{tabular}

Note. $90 \%$ CIs of correlation coefficients in parentheses.

${ }^{\mathrm{a}}$ average across all days, ${ }^{\mathrm{b}}$ in $\%$. 


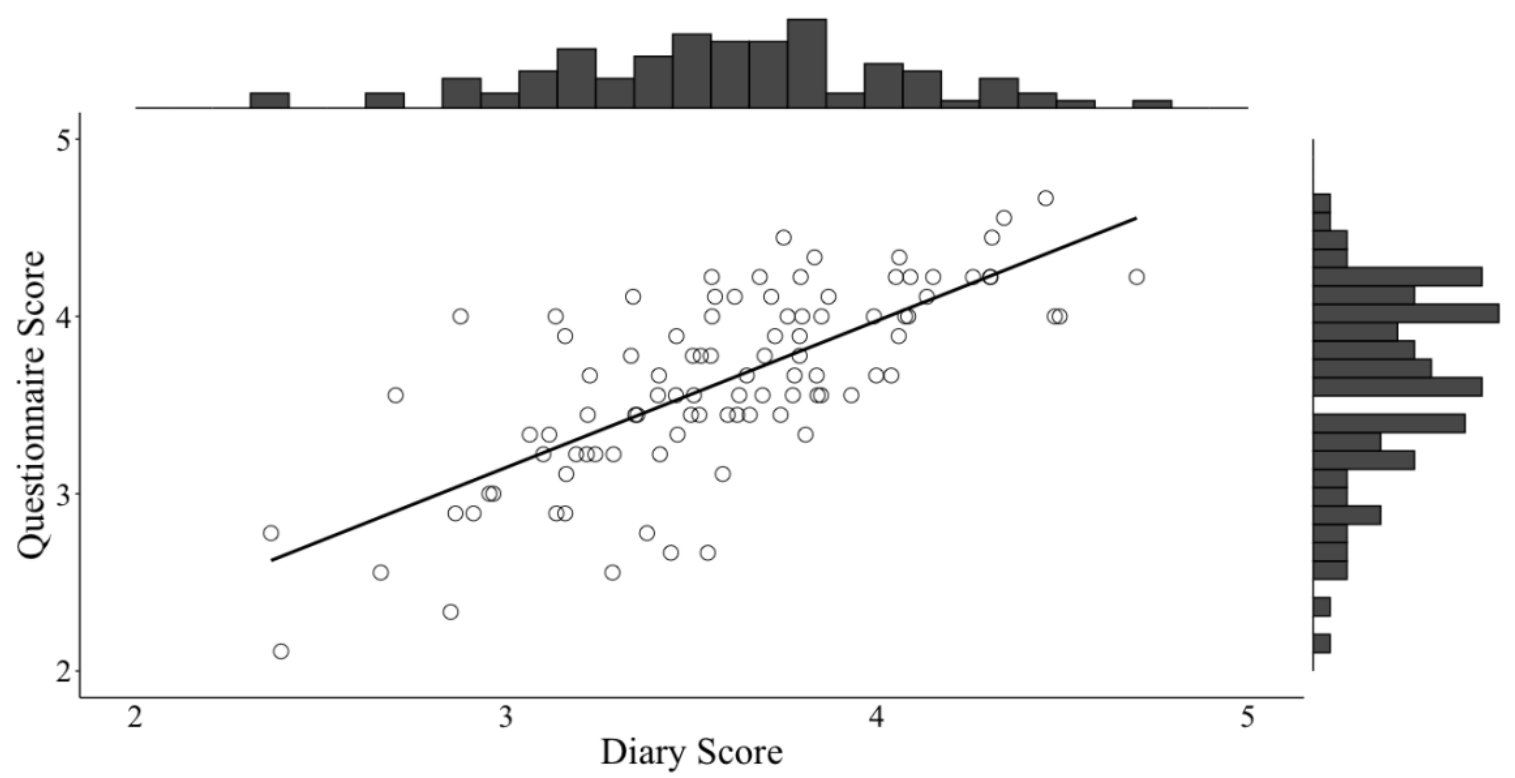

Figure 1. Scatterplot of the relation between the diary score and the questionnaire score $(r=.73$, CI $[.64, .83])$ with marginal histograms for both scores.

Both the questionnaire score $(r=.19$, CI $[.02, .43])$ and the diary score $(r=.29$, CI $[.12, .51])$ correlated positively with the percentage of days on which the learning goal was achieved (see Figure 2). The hierarchical regression revealed that the diary score added $9 \%$ (CI $[1 \%, 25 \%])$ variance to the explanation of inter-individual differences in goal achievement (see Table 2). The diary score also explained intra-individual differences in goal achievement: In general, students were between 1.40 and 1.77 times more likely to achieve their daily learning goal on days on which they reported their volitional control to be one unit larger. However, the evidence also suggested that students differed in the strength of the association between volitional control and learning success as indicated by the effect variability. As for the exam, neither the questionnaire score nor the diary score explained inter-individual performance differences (see Table 3). 

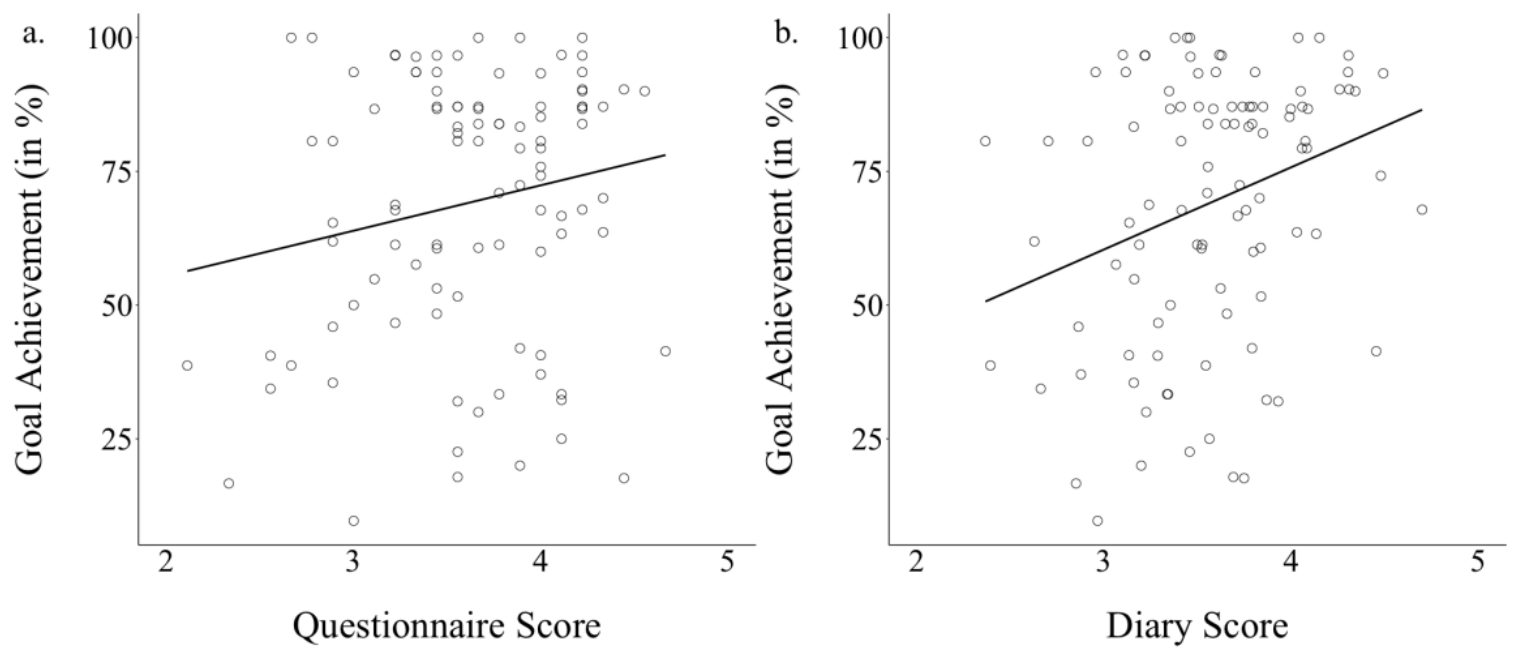

Figure 2. Scatterplots of the relation between average daily goal achievement and volitional control. a) The questionnaire had a weak positive correlation with daily goal achievement $(r=.19$, CI $[.02, .43])$, b) The diary score correlated moderately with daily goal achievement $(r=.29$, CI $[.12, .51])$.

To disentangle the contribution of volitional control from that of prior learning success, we tested whether the pattern of results would remain the same when controlling for students' performance in the intermediate exam. Prior academic performance can be considered as an aggregate proxy for factors contributing to current academic achievement. It is the single most important predictor of academic success and has been suggested as the control measure of choice when wanting to demonstrate the utility of other psychological predictors (Richardson et al., 2012). In the current dataset, performance in the intermediate exam accounted for $46 \%-81 \%$ of the variance in final exam performance (cf. Table 1). However, the data did not support the assumption of a positive association between prior performance and the average achievement of daily 
learning goals. Entering performance in the intermediate exam as a first step into the hierarchical regressions on daily goal achievement and exam performance did not change the pattern of results.

Table 2. Results of the Logistic Multilevel Regression Analysis on Daily Goal Achievement.

\begin{tabular}{|c|c|c|}
\hline & \multicolumn{2}{|c|}{$\begin{array}{c}\text { Daily Goal Achievement }(0=\text { not achieved, } 1= \\
\text { achieved })\end{array}$} \\
\hline & Step 1 & Step 2 \\
\hline \multicolumn{3}{|l|}{ Between-level } \\
\hline Threshold & $-0.67[-0.82,-0.45]$ & $-0.69[-0.84,-0.46]$ \\
\hline Questionnaire Score & $0.25[-0.03,0.67]$ & $-0.12[-0.53,0.51]$ \\
\hline Diary Score & & $0.59[0.10,1.36]$ \\
\hline $\mathrm{R}^{2}$ & $.02[.00, .08]$ & $.11[.01, .41]$ \\
\hline \multicolumn{3}{|l|}{ Within-level } \\
\hline Diary Score & & $0.43[0.34,0.57]$ \\
\hline OR & & $1.54[1.40,1.77]$ \\
\hline \multicolumn{3}{|l|}{ Random Effects } \\
\hline SD(Intercept) & & $0.46[0.40,0.56]$ \\
\hline SD(Diary Score) & & $0.22[0.10,0.45]$ \\
\hline
\end{tabular}

Note. $90 \%$ CIs for all parameters in parentheses. OR = odds ratio.

Table 3. Results of the Multilevel Regression Analysis on Exam Performance.

\begin{tabular}{|c|c|c|}
\hline & \multicolumn{2}{|c|}{ Exam Performance (in \%) } \\
\hline & Step 1 & Step 2 \\
\hline
\end{tabular}




\begin{tabular}{|c|c|c|}
\hline Intercept & $79.34[77.59,82.22]$ & $79.39[77.60,82.20]$ \\
\hline Questionnaire Score & $2.26[-1.11,7.85]$ & $1.00[-4.18,9.04]$ \\
\hline Diary Score & & $2.14[-3.51,11.17]$ \\
\hline $\mathrm{R}^{2}$ & $.01[.00, .11]$ & $.03[.00, .14]$ \\
\hline
\end{tabular}

Note. $90 \%$ CIs for all parameters in parentheses. Both volitional control scores are centered to make the intercept interpretable.

\section{Discussion}

This study empirically tested the assumption that volitional control explains individual differences in learning success. We compared two common assessment approaches, namely an offline questionnaire measure and an online learning diary measure of volitional control. The achievement of daily learning goals - our proximal measure of learning success - was measured objectively via log-files. We found that a volitional control score obtained from daily assessments explained inter- as well as intraindividual variance in daily goal achievement. Moreover, the daily reports explained substantial variance in inter-individual differences over and above the offline self-reports of volitional control. Our results, thus, highlight the advantages of daily assessments of volitional control.

Our results provide initial evidence that data from learning diaries, a common online assessment tool used in research on SRL processes (cf. Klug et al., 2011), explains substantial variance in students' average daily goal achievement. Considering that academic achievement of course has multiple determinants that range from intellective (e.g., prior knowledge) to non-intellective factors (e.g., motivation) (Richardson et al., 2012), it is noteworthy that volitional control could explain approximately a tenth of this 
variance. While previous learning diary studies investigated the relation between volitional control and subjective measures of learning success (e.g., satisfaction with learning), ours is the first to relate these data to an objective assessment of daily goal achievement. It is important to evaluate the predictive validity of daily online assessments, as they are considerably more effortful than one-off offline assessments (Trull \& Ebner-Priemer, 2013). In contrast to previous meta-analytical findings (Dent \& Koenka, 2016; Richardson et al., 2012), our study provided little support for the assumption that an offline questionnaire measure of volitional control could explain a substantial portion of the variance in goal achievement. This is surprising because the questionnaire was filled out after the online assessment period, which means that students' perceptions of accomplishment could have biased their self-reports towards a stronger association with volitional control. Our results, thus, indicate that online selfreport assessments of volitional control are sometimes preferable over offline assessments for the explanation of inter-individual differences in the achievement of learning goals.

Why could the volitional control score from diary data but not from questionnaire data explain inter-individual differences in students' goal achievement? A good framework for understanding the empirical non-alignment of different types of selfreports is the idea that different assessment strategies tap different modes of people's conscious self (Conner \& Barrett, 2012). Both of our assessments measured the remembering self, since the diaries were filled out after learning rather than during the learning session. Nevertheless, the daily assessments are more strongly based on episodic memory of individual events of volitional control than the reports in the questionnaire. 
The latter are strongly influenced by students' prior knowledge that acts as a schema for reconstructing critical events (see Shing \& Brod, 2016). Thus, the offline assessment biases the volitional control score towards reflecting students' beliefs of their typical behavior, whereas the online assessment is much more based on situation-specific appraisals. Our findings suggest that inter-individual differences in daily learning success are better explained by an aggregate of situation-specific appraisals rather than by beliefs about one's typical behavior.

We could further show that students reported varying degrees of volitional control on a day-to-day basis and that these fluctuations were coupled with students' likelihood of goal achievement on a particular day. It is a unique asset of intensive longitudinal data that it allows to study such intra-individual couplings (Bolger \& Laurenceau, 2013). Learning diaries are, thus, increasingly used in the context of models that conceptualize SRL as a dynamic state (Klug et al., 2011). Our results provide further support for the idea that volitional control has state-like features that are apparent in the substantial intraindividual variance we found in students' diary scores. The fact that these day-to-day fluctuations systematically predicted the likelihood of goal achievement on a particular day makes it hard to dismiss the intra-individual variance as measurement error. Previous learning diary studies that examined the correlation between volitional control and learning success relied on self-reports for both (e.g., Liborius et al., 2019; Schmitz \& Wiese, 2006). This leaves open the possibility that students' reports on perceived control and perceived learning success were biased by their overall study satisfaction, thereby inflating the correlation between the self-reported volitional control and learning success. Our study substantially reduced this risk by using an objective measure of daily learning 
success by means of logfile data and, thus, makes an important contribution to the existing literature on intra-individual couplings between aspects of SRL and learning success.

Another noteworthy finding of the present study is that, while the diary data provided incremental validity over the questionnaire data, the two types of data shared substantial variance (i.e., shared variances of $46 \%-81 \%$ ). While we are not aware of studies that have examined this for volitional control, previous findings on other psychological constructs indicate that one-off questionnaire data and aggregated real-time data typically share little variance in many domains (Rausch, 2014). In our study, both the questionnaire and the diary score reflect typical behavior, although they are based on different sources of information (i.e., students' beliefs vs. students' situation-specific appraisals, as described above). Another important consideration is the intentional match between both assessment types. Since the goal of our study was to provide a fair comparison of the two assessments, we designed diaries and posttest questionnaire to measure the same facets of volitional control, although items were not identical. The diaries needed to be adjusted to the daily rating of volitional control, whereas the questionnaire assessed the frequency of past regulation. However, both assessments were tailored to the same learning context (i.e., exam preparation). Since the questionnaire was administered directly following the daily assessment period, it is plausible to assume that students' reports on typical control frequency were heavily influenced by their experiences during the previous four weeks of daily assessments. The fact that, despite their high convergence, the diary data explained substantial variance in goal achievement over the questionnaire data makes a strong case for its incremental validity. 
Our study has several limitations. First, it should be noted that our research was conducted in a highly selective sample of university students with above-average cognitive abilities, which might have led to less recall biases in the self-reports than would be expected in other populations. The study was also conducted in a very specific learning context that led to our focus on a purely quantitative learning goal (i.e., the number of questions students intended to answer). Learning on the digital platform is based on the idea that students should answer old exam questions as a means of repeating (rather than newly acquiring) the knowledge needed for the exam. Our findings should, thus, be tested in different populations and for different learning goals to determine their generalizability. Second, students' daily self-reports in the learning diaries were assessed shortly after the achievement or non-achievement of their daily learning goals. While this is an integral feature of the learning diary method, we cannot rule out that students kept track of their learning success and aligned their self-reports accordingly. Similarly, reports in the posttest questionnaire were most likely dependent on reports during the ambulatory assessment. While this might have led to more accurate retrospective assessments, it could have also artificially inflated the correlation between the assessment types. Third, although we can conclude with high certainty that there is a positive association between volitional control and achievement of daily learning goals, the magnitude of this association remains quite uncertain. For instance, the true amount of variance that the diary score explains in daily goal achievement could, with high probability, range anywhere between $1.44 \%$ and $26.01 \%$, as marked by the CI of the correlation between the two variables. Future research will need to gather more data on the relation between volitional control and learning success to obtain more precise 
estimates of the parameters. Fourth, our analyses do not allow to draw causal conclusions about the relation between volitional control and learning success. We controlled for intermediate exam performance as a global indicator of prior academic achievement, but it was not associated with daily goal achievement. Future studies should consider controlling for more situation-specific factors.

Finally, neither the diary score nor the questionnaire score predicted exam performance, the reasons for which remain speculative at this point. For instance, social desirability could be generally limiting the validity of the self-reports but is very rarely considered in SRL research (but see Mouratidis et al., 2013, for an exception). Further, exam grades were self-reported, hence we do not know with certainty whether they were always provided correctly. It should, however, also be noted that the point estimate of the correlation we found between the questionnaire score and exam performance was well within the range reported for the correlation between offline measures of SRL and academic performance (cf. Dent \& Koenka, 2016). Overall, our estimates are to be considered conservative due to our use of composite scores of volitional control. We note that we deliberately decided to use composite scores rather than latent factors because we are not certain that a reflective measurement model (assuming substantial covariation among the facets of volitional control) is warranted in the present scenario. It seems plausible, that a formative measurement model underlies the structure of volitional control, which would render the interpretation from finings based on a reflective measurement models potentially biased (see Rhemtulla et al., 2020).

In summary, the present study supports the claim that students' volitional control of their learning explains individual differences in academic performance (Corno, 1993). 
Our findings demonstrate, however, that the assessment method has a decisive impact on the predictive validity of volitional control measures. Learning diaries, albeit more effortful than filling out a questionnaire once, provide added value for the explanation of inter- as well as intra-individual differences in the achievement of learning goals. More systematic comparisons of different assessment methods in the context of SRL are needed to enable researchers as well as practitioners to capitalize on the most informative methods to assess different aspects of people's self-regulated learning behavior.

\section{Open Practices Statement}

The present study used data collected in the ACHILLES project, which included a self-regulation intervention (see Breitwieser et al., 2020; an overview of the procedure and all materials used as part of the project can be found at https://osf.io/tg7zd/?view_only=58ad6b4f10994f878625d713f2069a0c). The analyses reported in this manuscript were not pre-registered. We used all eligible data of the ACHILLES project for the current analyses, which is why we did not perform an a priori power analysis. The data, materials, and analysis scripts that are needed to reproduce our results can be found at https://osf.io/s9et6/?view_only=c079f61909f444a88107bebf26db7b25. 


\section{References}

Boekaerts, M., \& Corno, L. (2005). Self-regulation in the classroom: A perspective on assessment and intervention. Applied Psychology, 54(2), 199-231.

https://doi.org/10.1111/j.1464-0597.2005.00205.x

Bolger, N., \& Laurenceau, J.-P. (2013). Intensive Longitudinal Methods. The Guilford Press.

Breitwieser, J., Neubauer, A. B., Schmiedek, F., \& Brod, G. (2020). Self-Regulation prompts promote the achievement of learning goals - but only briefly: Uncovering hidden dynamics in the effects of a psychological intervention. PsyArxiv. https://doi.org/10.31234/osf.io/bz49m

Conner, T. S., \& Barrett, L. F. (2012). Trends in ambulatory self-report: The role of momentary experience in psychosomatic medicine. Psychosomatic Medicine, 74(4), 327-337. https://doi.org/10.1097/PSY.0b013e3182546f18

Conner, T. S., \& Mehl, M. R. (2015). Ambulatory assessment - Methods for studying everyday life. In R. Scott, S. Kosslyn, \& N. Pinkerton (Eds.), Emerging Trends in the Social and Behavioral Sciences (pp. 1-15). Wiley. https://doi.org/10.1002/9781118900772.etrds0010

Corno, L. (1993). The best-laid plans: Modern conceptions of volition and educational research. Educational Researcher, 22(2), 14-22. https://doi.org/10.3102/0013189X022002014

Corno, L. (1994). Student volition and education: Outcomes, influences, and practices. In D. H. Schunk \& B. J. Zimmerman (Eds.), Self-Regulation of Learning and Performance: Issues and Educational Applications (pp. 229-254). Lawrence 
Erlbaum Associates, Inc.

Corno, L., \& Kanfer, R. (1993). The role of volition in learning and performance. Review of Research in Education, 19(1), 301-341. https://doi.org/10.3102/0091732X019001301

Dent, A. L., \& Koenka, A. C. (2016). The relation between self-regulated learning and academic achievement across childhood and adolescence: A meta-analysis. Educational Psychology Review, 28(3), 425-474. https://doi.org/10.1007/s10648015-9320-8

Dörrenbächer, L., \& Perels, F. (2015). Volition completes the puzzle: Development and evaluation of an integrative trait model of self-regulated learning. Frontline Learning Research, 3(4), 14-36. https://doi.org/10.14786/flr.v3i4.179

Dörrenbächer, L., \& Perels, F. (2016). More is more? Evaluation of interventions to foster self-regulated learning in college. International Journal of Educational Research, 78, 50-65. https://doi.org/10.1016/j.ijer.2016.05.010

Duckworth, A. L., \& Kern, M. (2011). A meta-analysis of convergent validity evidence for self-control measures. Journal of Personality Research, 45(3), 259-268. https://doi.org/10.1038/jid.2014.371

Duckworth, A. L., Taxer, J. L., Eskreis-Winkler, L., Galla, B. M., \& Gross, J. J. (2019). Self-control and academic achievement. Annual Review of Psychology, 70(1), 373399. https://doi.org/10.1146/annurev-psych-010418-103230

Klug, J., Ogrin, S., Keller, S., Ihringer, A., \& Schmitz, B. (2011). A plea for selfregulated learning as a process: Modelling, measuring and intervening. Psychological Test and Assessment Modeling, 53(1), 51-72. 
Korotitsch, W. J., \& Nelson-Gray, R. O. (1999). An overview of self-monitoring research in assessment and treatment. Psychological Assessment, 11(4), 415-425. https://doi.org/10.1037/1040-3590.11.4.415

Kuhl, J. (1985). Volitional mediators of cognition-behavior consistency: Self-regulatory processes and action versus state orientation. In J. Kuhl \& J. Beckmann (Eds.), Action Control (pp. 101-128). Springer. https://doi.org/10.1007/978-3-642-697463_6

Kuhl, J. (2000). A functional-design approach to motivation and self-regulation: The dynamics of personality systems interactions. In M. Boekaerts, P. R. Pintrich, \& M. Zeidner (Eds.), Handbook of Self-Regulation (pp. 111-169). Academic Press. https://doi.org/https://doi.org/10.1016/B978-012109890-2/50034-2

Liborius, P., Bellhäuser, H., \& Schmitz, B. (2019). What makes a good study day? An intraindividual study on university students' time investment by means of timeseries analyses. Learning and Instruction, 60, 310-321. https://doi.org/10.1016/j.learninstruc.2017.10.006

McCann, E. J., \& Garcia, T. (1999). Maintaining motivation and regulating emotion: Measuring individual differences in academic volitional strategies. Learning and Individual Differences, 11(3), 259-279. https://doi.org/10.1016/S10416080(99)80003-X

Mouratidis, A., Vansteenkiste, M., Michou, A., \& Lens, W. (2013). Perceived structure and achievement goals as predictors of students' self-regulated learning and affect and the mediating role of competence need satisfaction. Learning and Individual Differences, 23(1), 179-186. https://doi.org/10.1016/j.lindif.2012.09.001 
Muthén, L. K., \& Muthén, B. O. (2017). Mplus User's Guide (Eighth).

O’Brien, R. M. (2007). A caution regarding rules of thumb for variance inflation factors. Quality and Quantity, 41(5), 673-690. https://doi.org/10.1007/s11135-006-9018-6

Panadero, E., Klug, J., \& Järvelä, S. (2016). Third wave of measurement in the selfregulated learning field: When measurement and intervention come hand in hand. Scandinavian Journal of Educational Research, 60(6), 723-735. https://doi.org/10.1080/00313831.2015.1066436

Perels, F., Otto, B., Landmann, M., Hertel, S., \& Schmitz, B. (2007). Self-regulation from a process perspective. Zeitschrift Für Psychologie / Journal of Psychology, 215(3), 194-204. https://doi.org/10.1027/0044-3409.215.3.194

Pintrich, P. R. (2004). A conceptual framework for assessing motivation and SRL in college students. Educational Psychology Review, 16(4), 385-407.

Pintrich, P. R., Wolters, C. a, \& Baxter, G. P. (2000). Assessing metacognition and selfregulated learning. Issues in the Measurement of Metacognition, 43-97. http://digitalcommons.unl.edu/cgi/viewcontent.cgi?article=1002\&context=burosmet acognition

Rausch, A. (2014). Using diaries in research on work and learning. In C. Harteis, A. Rausch, \& J. Seifried (Eds.), Discourses on professional learning: On the boundary between learning and working (pp. 341-366). Springer. https://doi.org/10.1007/97894-007-7012-6_17

Rhemtulla, M., van Bork, R., \& Borsboom, D. (2020). Worse than measurement error: Consequences of inappropriate latent variable measurement models. Psychological Methods, 25(1), 30-45. https://doi.org/10.1037/met0000220 
Richardson, M., Abraham, C., \& Bond, R. (2012). Psychological correlates of university students' academic performance: A systematic review and meta-analysis. Psychological Bulletin, 138(2), 353-387. https://doi.org/10.1037/a0026838

Robinson, M. D., \& Clore, G. L. (2002). Belief and feeling: Evidence for an accessibility model of emotional self-report. Psychological Bulletin, 128(6), 934-960. https://doi.org/10.1037/0033-2909.128.6.934

Rovers, S. F. E., Clarebout, G., Savelberg, H. H. C. M., de Bruin, A. B. H., \& van Merriënboer, J. J. G. (2019). Granularity matters: Comparing different ways of measuring self-regulated learning. Metacognition and Learning, 14(1). https://doi.org/10.1007/s11409-019-09188-6

Saunders, B., Milyavskaya, M., Etz, A., Randles, D., \& Inzlicht, M. (2018). Reported self-control is not meaningfully associated with inhibition-related executive function: A Bayesian Analysis. Collabra: Psychology, 4(1), 39. https://doi.org/10.1525/collabra.134

Schmitz, B., \& Perels, F. (2011). Self-monitoring of self-regulation during math homework behaviour using standardized diaries. Metacognition and Learning, 6(3), 255-273. https://doi.org/10.1007/s11409-011-9076-6

Schmitz, B., \& Skinner, E. (1993). Perceived control, effort, and academic performance: Interindividual, intraindividual, and multivariate time-series analyses. Journal of Personality and Social Psychology, 64(6), 1010-1028. https://doi.org/10.1037/00223514.64.6.1010

Schmitz, B., \& Wiese, B. S. (2006). New perspectives for the evaluation of training sessions in self-regulated learning: Time-series analyses of diary data. 
Contemporary Educational Psychology, 31(1), 64-96.

https://doi.org/10.1016/j.cedpsych.2005.02.002

Schwarzer, R., \& Jerusalem, M. (1999). Skalen zur Erfassung von Lehrer- und Schülermerkmalen. In Dokumentation der psychometrischen Verfahren im Rahmen der Wissenschaftlichen Begleitung des Modellversuchs Selbstwirksame Schulen.

Shing, Y. L., \& Brod, G. (2016). Effects of prior knowledge on memory: Implications for education. Mind, Brain, and Education, 10(3), 153-161.

https://doi.org/10.1111/mbe.12110

Tourangeau, R. (2000). Remembering what happened: Memory errors and survey reports. In A. A. Stone, J. S. Turkkan, C. A. Bachrach, J. B. Jobe, H. S. Kurtzman, \& V. S. Cain (Eds.), The science of self-report: Implications for research and practice (pp. 29-47). Lawrence Erlbaum.

Trull, T. J., \& Ebner-Priemer, U. (2013). Ambulatory assessment. Annual Review of Clinical Psychology, 9(1), 151-176. https://doi.org/10.1146/annurev-clinpsy050212-185510

Veenman, M. V. J. (2011). Alternative assessment of strategy use with self-report instruments: A discussion. Metacognition and Learning, 6(2), 205-211. https://doi.org/10.1007/s11409-011-9080-X

Wallin, P., \& Adawi, T. (2018). The reflective diary as a method for the formative assessment of self-regulated learning. European Journal of Engineering Education, 43(4), 507-521. https://doi.org/https://doi.org/10.1080/03043797.2017.1290585

Wennerhold, L., \& Friese, M. (2020). Why self-report measures of self-control and inhibition tasks do not substantially correlate. Collabra: Psychology, 6(1), 9. 
https://doi.org/10.1525/collabra.276

Winne, P. H., \& Perry, N. E. (2000). Measuring self-regulated learning. In M. Boekaerts, P. R. Pintrich, \& M. Zeidner (Eds.), Handbook of Self-Regulation (pp. 531-566). Academic Press. https://doi.org/10.1016/B978-012109890-2/50045-7

Wolters, C. A. (1999). The relation between high school students' motivational regulation and their use of learning strategies, effort, and classroom performance. Learning and Individual Differences, 11(3), 281-299. https://doi.org/10.1016/S1041-6080(99)80004-1

Wolters, C. A. (2003). Regulation of motivation: Evaluating an underemphasized aspect of self-regulated learning. Educational Psychologist, 38(4), 189-205. https://doi.org/10.1207/S15326985EP3804_1

Zimmerman, B. J. (2000). Attaining self-regulation: A social cognitive perspective. In M. Boekaerts, P. R. Pintrich, \& M. Zeidner (Eds.), Handbook of Self-Regulation (pp. 13-39). Academic Press. 


\section{Appendices}

Appendix A. List of Items from the Daily Diaries.

\begin{tabular}{|c|c|}
\hline Item Text & Facet \\
\hline $\begin{array}{l}\text { During my studies today, I monitored how far I am from my daily } \\
\text { workload. } \\
\text { [Ich habe heute während des Lernens darauf geachtet, wie weit ich noch } \\
\text { von meinem Tagespensum entfernt bin.] }\end{array}$ & Self-monitoring \\
\hline $\begin{array}{l}\text { During my studies today, I monitored if I was still focused. } \\
\text { [Ich habe heute während des Lernens darauf geachtet, ob ich noch } \\
\text { konzentriert bei der Sache bin.] }\end{array}$ & \\
\hline $\begin{array}{l}\text { During my studies today, I monitored if I really understood everything. } \\
\text { [Ich habe heute während des Lernens darauf geachtet, ob ich auch } \\
\text { wirklich alles verstanden habe.] }\end{array}$ & \\
\hline $\begin{array}{l}\text { During my studies today, I monitored if I still made an effort while } \\
\text { learning. } \\
\text { [Ich habe heute darauf geachtet, ob ich mir beim Lernen noch Mühe } \\
\text { gebe.] }\end{array}$ & \\
\hline $\begin{array}{l}\text { I controlled my worries and feelings today so that they could not stop me } \\
\text { from studying. } \\
\text { [Ich habe meine Sorgen und Gefühle heute so kontrolliert, dass sie mich } \\
\text { nicht vom Lernen abhalten konnten.] }\end{array}$ & Regulation \\
\hline $\begin{array}{l}\text { When I caught myself doing something different while studying (e.g. } \\
\text { surfing the internet), I immediately returned to studying. } \\
\text { [Wenn ich mich dabei erwischt habe, wie ich während des Lernens etwas } \\
\text { anderes getan habe (z.B. im Internet surfen), bin ich sofort zum Lernen } \\
\text { zurückgekehrt.] }\end{array}$ & \\
\hline $\begin{array}{l}\text { When I was tired of it, I motivated myself to continue studying. } \\
\text { [Wenn ich keine Lust mehr hatte, habe ich mich motiviert, trotzdem } \\
\text { weiterzulernen.] }\end{array}$ & \\
\hline
\end{tabular}


When my thoughts wandered away while studying, I immediately focused on learning again.

[Wenn während des Lernens meine Gedanken abgeschweift sind, habe ich mich gleich wieder auf das Lernen fokussiert.]

Today, I have put off learning for a long time.

Procrastination

[Ich habe das Lernen heute lange vor mir hergeschoben.]

Appendix B. List of Items from the Posttest Questionnaire.

\begin{tabular}{|c|c|}
\hline Item Text & Facet \\
\hline $\begin{array}{l}\text { When studying, I make sure that I still make an effort to answer the } \\
\text { questions correctly. } \\
\text { [Ich achte beim Lernen darauf, ob ich mir noch Mühe gebe, die } \\
\text { Fragen richtig zu kreuzen.] }\end{array}$ & Self-monitoring \\
\hline $\begin{array}{l}\text { When I'm studying, I make sure that I'm still focused. } \\
\text { [Ich achte beim Lernen darauf, ob ich noch konzentriert bei der Sache } \\
\text { bin.] }\end{array}$ & \\
\hline $\begin{array}{l}\text { When studying, I monitor if I only read the material listlessly. } \\
\text { [Ich achte beim Lernen darauf, ob ich den Stoff nur noch lustlos } \\
\text { durchlese.] }\end{array}$ & \\
\hline $\begin{array}{l}\text { I adapt my learning technique to the respective requirements. } \\
\text { [Ich passe meine Lerntechnik den jeweiligen Anforderungen an.] }\end{array}$ & Regulation \\
\hline $\begin{array}{l}\text { When I lose interest in studying, I can motivate myself to continue } \\
\text { studying } \\
\text { [Wenn ich beim Lernen die Lust verliere, kann ich mich motivieren, } \\
\text { trotzdem weiterzulernen.] }\end{array}$ & \\
\hline $\begin{array}{l}\text { When I am interrupted while studying, I can easily find my way back } \\
\text { to a concentrated way of working. } \\
\text { [Wenn ich beim Lernen unterbrochen werde, finde ich problemlos zu } \\
\text { einer konzentrierten Arbeitsweise zurück.] }\end{array}$ & \\
\hline
\end{tabular}




\begin{tabular}{|l|l|}
\hline $\begin{array}{l}\text { I put learning off. } \\
\text { [Ich schiebe das Lernen vor mir her.] }\end{array}$ & \multirow{2}{*}{ Procrastination } \\
\cline { 1 - 2 } $\begin{array}{l}\text { I am an incurable time-waster when learning. } \\
\text { [Beim Lernen bin ich ein unheilbarer Zeitverschwender.] }\end{array}$ & \\
\cline { 1 - 2 } $\begin{array}{l}\text { I promise myself to learn, but then put my feet up. } \\
\text { [Ich verspreche mir selbst, zu lernen, lege dann aber die Füße hoch.] }\end{array}$ & \\
\hline
\end{tabular}

